Revista de Derecho YACHAQ

ISSN: 1817-597x (impresa) / ISSN: 2707-1197 (en linea)

Centro de Investigación de los Estudiantes de Derecho (CIED)

Universidad Nacional de San Antonio Abad del Cusco

N. ${ }^{\circ} 10-2019$

[pp. 95-108]

Fecha de recepción: 09/08/19

Fecha de aceptación: 14/09/19

\title{
El humor en los tiempos de cólera: una reflexión sobre la libertad de expresión en el ámbito artístico
}

\author{
The Humor in the Cholera's Times: \\ A Reflection on The Freedom of Speech in The Arts
}

\author{
Néstor Daniel Loyola Ríos ${ }^{[*]}$
}

\begin{abstract}
RESUMEN. El autor desarrolla el contenido del derecho a la libertad de expresión en su modalidad artística y señala que su ejercicio entraña a su vez el reconocimiento de un derecho implícito a la irreverencia. También, sostiene que el arte, como herramienta de comunicación social, debe ser entendido en el marco de un Estado constitucional cultural que garantiza la autorrealización del ser humano y el fortalecimiento de su capacidad crítica y reflexiva mediante el acceso a la cultura, la ciencia y las artes. Finalmente, se proponen casos emblemáticos a nivel comparado que evidencian los límites a este derecho, así como los criterios y métodos para resolver las colisiones con otros derechos fundamentales.

ABSTRACT. The author develops the content of the right to freedom of expression in its artistic form and points out that its exercise also entails the recognition of an implicit right to irreverence. He also maintains that art, as a tool of social communication, must be understood within the framework of a constitutional cultural state that guarantees the self-realization of the human being and the strengthening of its critical and reflective capacity through access to culture, science and the arts. Finally, emblematic cases are proposed at a compared level that show the limits to this right, as well as the criteria and methods to resolve the collisions whit other fundamental rights.
\end{abstract}

PALABRAS CLAVES: libertad de expresión, arte, cultura, sátira.

KEY WORDS: freedom of speech, art, culture, satire.

[*] Abogado por la Universidad Nacional de Trujillo. Segunda Especialidad en Derecho del Trabajo y de la Seguridad Social por la Pontificia Universidad Católica del Perú. Egresado de la Maestría en Derecho Constitucional por la Pontificia Universidad Católica del Perú. Abogado en la Adjuntía en Asuntos Constitucionales de la Defensoría del Pueblo. Autor de diversos artículos de investigación jurídica y expositor en materia constitucional. Este trabajo contiene opiniones realizadas a título personal del autor.

Contacto: nestorloyola5@gmail.com 


\section{INTRODUCCIÓN}

Las ideas u opiniones expresadas a través del arte se han hecho cada vez más frecuentes en nuestros tiempos y no pasan desapercibidas en la vida cotidiana. Tan solo bastaría revisar, por ejemplo, las diversas caricaturas contenidas en la mayoría de periódicos y revistas de circulación nacional, las parodias humorísticas difundidas en los canales de televisión, las canciones de género punk, urbano, etc., las películas, los poemas, las obras de teatro, los chistes, las fotografías u otras representaciones afines. Todas ellas, qué duda cabe, forman parte del derecho fundamental a la libertad de expresión.

Sin embargo, el ejercicio de este derecho plantea una discusión especial en el ámbito constitucional, por cuanto no se trata de cualquier clase de expresión, sino una amparada en el polémico mundo de las artes, cuyo ejercicio libre suele trastocar las más íntimas y mayoritarias concepciones morales o religiosas que tienen las personas o una comunidad en general.

En ese sentido, el desarrollo del presente opúsculo pretende abordar los contenidos de la libertad de expresión artística (ciertamente olvidados por la jurisprudencia y gran parte de la doctrina peruana), el nacimiento de un derecho a la irreverencia, sus límites, la censura, la rectificación y algunos criterios normativos relevantes, con la finalidad de que contribuyan en la resolución de los conflictos, en el marco de un Estado constitucional que promueve y defiende el acceso a la cultura.

\section{EL DERECHO A LA LIBERTAD DE EXPRE- SIÓN Y EL ARTE COMO INSTRUMENTO DE COMUNICACIÓN}

Para comprender los alcances de la libertad de expresión artística es necesario ir delimitando qué significa esta referencia al concepto de arte, quiénes pueden ejercerlo y qué se protege, a partir de su regulación en los textos normativos nacionales e internacionales.

\subsection{Entre lo artístico y lo jurídico: algunos apuntes necesarios}

El estudio del derecho en general, y del derecho constitucional en particular, implica tener un enfoque interdisciplinario con diversas áreas del conocimiento que distan de lo estrictamente jurídico, pero que son sumamente necesarias para entender cómo está regulado cierta parcela de la realidad. Por ello, coincidimos con Marcial Rubio (2009) cuando sostiene que el derecho es una disciplina cuyo conocimiento es compartido por especialistas y legos, lo cual, como es fácil suponer, engendra diversos problemas de comprensión y comunicación. Así, por ejemplo, si se quiere conocer los alcances de la libertad religiosa o el principio de libre competencia, será necesario interiorizar, cuando menos, algunos conceptos básicos sobre teología o las ciencias económicas, pues de muy poco serviría explicar qué significan tales categorías si se ignoran las prácticas religiosas o el comportamiento de los agentes económicos en el mercado, respectivamente.

Lo mismo sucede en el caso de la libertad de expresión artística, en el que tener una noción sobre lo que es arte se vuelve imperioso. Sin embargo, el arte es uno de esos conceptos que siempre ha estado presente en el decurso de la historia de la humanidad, pero que no ha sido sencillo definirla por los grandes pensadores y filósofos de la época. Inicialmente, los griegos y romanos lo asociaban a lo estético y lo moral, enarbolando la desnudez humana como punto de partida de su visión sobre el mundo. Luego, en la edad media, esta misma idea fue censurada bajo concepciones teocráticas y realistas, para después reivindicar con el movimiento renacentista y humanista la esencia del ser y su naturaleza ontológica.

En ese contexto, consideramos que el arte no debe ser protegido por expresar lo bueno o, lo que es lo mismo, dictar preceptos morales (Martínez, 2014). Se trata de un libre juego de las facultades del entendimiento y la intuición, que son enlazadas mediante la imaginación. Por tanto, el juicio estético representa una facultad subjetiva, de gusto o disgusto, frente a la obra de arte, en donde la existencia o no del objeto representado es indiferente $y$, por ende, sin interés alguno (Cordero, 1999).

El arte es una forma muy particular de comunicación que merece también protección por nuestro ordenamiento constitucional. $Y$ es que como sostiene Faúndez (2004): «Para comunicar nuestras 
ideas y sentimientos, la expresión artística constituye una forma más refinada y sofisticada que la expresión verbal» (p. 188). O acaso, alguien podría negar la expresividad y emotividad que genera apreciar obras como La persistencia de la memoria de Salvador Dalí, recitar los versos de Los dados eternos de César Vallejo o simplemente escuchar un Contigo Perú interpretada en las voces de Arturo «Zambo» Cavero y don Óscar Avilés.

\subsection{Reconocimiento internacional y constitu- cional de la libertad de expresión artística}

\subsubsection{En el sistema internacional de pro- tección de los Derechos Humanos}

El artículo 19 de la Declaración Universal de Derechos Humanos reconoce en forma general que toda persona tiene derecho a la libertad de expresión y a no ser molestado a causa de sus opiniones. Sin embargo, a pesar de que no hace una mención explícita al arte como herramienta comunicativa, este puede hallar protección cuando se pone en relieve que el ejercicio de tal derecho puede realizarse «por cualquier medio de expresión». Distinto es lo que acaece con el Pacto Internacional de Derechos Civiles y Políticos, pues el artículo 19.2 consagra expresamente al elemento artístico como una vía a través de la cual las personas pueden difundir sus ideas. Así, también, la Convención Americana de Derechos Humanos señala literalmente en su artículo 13.1 que la libertad de expresión puede ser ejercida no solo por la palabra oral o escrita, sino también en «forma artística».

Una situación diferente rige a otros sistemas jurídicos continentales, ya que el Convenio para la Protección de los Derechos Humanos y de las Libertades Fundamentales opta simplemente por establecer una regulación genérica sobre la libertad de expresión en el artículo 10.1, debido al influjo de la Declaración Universal de Derechos Humanos en esa parte del hemisferio. Lo mismo sigue la Carta Africana sobre los Derechos Humanos y de los Pueblos al establecer en su disposición 9.2 que el derecho a expresar y difundir opiniones se ejerce sin otro límite que no sea la ley.

Todo lo anterior evidencia que, si bien el reconocimiento del arte como tal no está previsto taxativamente como una modalidad de expresión en algunos instrumentos internacionales, puede quedar comprendido a través de una cláusula abierta que cobija tanto las manifestaciones plasmadas en forma tradicional (oral o escrita) como aquellas que no lo son (artísticas o de cualquier otra índole).

\subsubsection{En la Constitución Política de 1993}

El artículo 2.4 de nuestra norma suprema recoge el derecho de libertad de expresión mediante «la palabra oral o escrita o la imagen», omitiendo precisar - por lo menos en la disposición normativa - a aquellas manifestaciones que surgen bajo las modalidades artísticas. Sin embargo, en virtud de la cuarta disposición final y transitoria de la Constitución, estimamos que estas formas de expresión encuentran protección constitucional, debido a lo prescrito en el artículo 13 de la Convención Americana y atendiendo a que el citado artículo constitucional no puede soportar una lectura restrictiva, habida cuenta de que las expresiones alcanzan también dimensiones gráficas.

\subsection{Naturaleza jurídica del Derecho a la liber- tad de expresión artística}

Determinar la ubicación de las manifestaciones artísticas en los instrumentos normativos no es un dato intrascendente, ya que durante años ha existido un interesante debate respecto a la inclusión del arte como un discurso protegido por la libertad de expresión. Veamos, entonces, estas teorías.

\subsubsection{La expresión artística como derecho autónomo}

Cierto sector de la doctrina aduce que las manifestaciones del arte no pueden estar comprendidas dentro del derecho a la libertad de expresión, pues bajo una concepción democrático política solo caben aquellas ideas u opiniones de connotada relevancia pública. En esa línea, Robert Bork (1971) señala que el amparo de la libertad de expresión se justifica en el bien público del autogobierno; mientras que la expresión artística 
se regocija en un asunto privado y subjetivo del artista, así como otras manifestaciones, decisiones o comunicaciones privadas ${ }^{[1]}$.

Por ello, el discurso artístico se halla inmerso en un derecho autónomo: la libertad de expresión artística, cuyo pensamiento crítico puede, incluso, carecer de interés público o revestir de alguna faz política, como sucede con el arte abstracto o vanguardista. En cualquiera de los casos, esta libertad fundamental tiene un contenido y límites propios.

\subsubsection{La expresión artística como derecho derivado de la libertad de expresión}

Es considerable la doctrina que sostiene que las manifestaciones artísticas son un vehículo más por donde transitan las ideas y opiniones de las personas. Por eso, admiten la existencia de un derecho a la libertad de expresión artística como especie del derecho continente a la libertad de expresión.

Tal es el caso de Alexander Meiklejohn (1961), para quien existían 4 tipos de expresiones que gozaban de protección en la primera enmienda constitucional: la educativa, la relativa a la filosofía y la ciencia, la artística o literaria y la referida a asuntos públicos. Mediante una extensión de la noción de lo político, el autor defiende la protección constitucional de la expresión artística, pues en su opinión tanto el arte como la literatura contribuyen al desarrollo intelectual del hombre, permitiéndole abrirse a nuevas ideas y convirtiéndolo en un sujeto capaz de pensar por sí mismo; en resumen, un sujeto capaz de autogobernarse.

Al respecto, cabe señalar que nuestra Constitución sigue esta postura, porque considera que la libertad de expresión artística es un derecho derivado de la libertad de expresión, configurando así una relación de especie-género. No obstante, como se desarrollará en los siguientes apartados, es una dependencia nominal, por cuanto la libertad de expresión artística posee un contenido autónomo.

\section{LIBERTAD DE EXPRESIÓN ARTÍSTICA: ¿CABE HABLAR DE UN DERECHO A LA IRREVERENCIA?}

\subsection{El Estado Constitucional de Cultura y la Presencia del Elemento Artístico}

Es conocido que el Estado constitucional se caracteriza por la convergencia de 3 elementos indispensables: la limitación del poder político, la protección de los derechos fundamentales y el reconocimiento del principio de supremacía de la Constitución. Sin embargo, para el jurista alemán Peter Häberle es la dimensión cultural la que permite reivindicar la esencia de la persona dentro del orden constitucional y entender la evolución social de toda una organización política.

Por ello, bajo su visión iusculturalista de la Constitución, sostiene que:

[L]a Constitución no se limita solo a ser un conjunto de textos jurídicos o un mero compendio de reglas normativas, sino la expresión de un cierto grado de desarrollo cultural, un medio de autorrepresentación propia de todo un pueblo, espejo de su legado cultural y fundamento de sus esperanzas y deseos. (Häberle, 2000, p. 34)

Para este autor, la cultura se expresa mediante la educación, la ciencia y el arte, formando un baremo especial en lo que a autonomía, libertad y distanciamiento de la coercibilidad estatal se refiere (Häberle, 2000). También, «crea a un tipo humano con rasgos psicológicos propios: el hombre culto, que por serlo, es más reflexivo y más crítico, y por tanto más libre» (Pau y Roca, 2009, p. 92). Y es que los textos constitucionales son ratio, pero también emotio, porque conectan al ser humano con los valores fundamentales de la sociedad y, a su vez, garantizan el hecho de poder ejercerlos y expresarlos. Su función es captar la conditio humana desde el lado emocional y, por tanto, dar también más constitución a la res pública desde este lado, dirigirse al ser humano desde el lado de lo irracional, de lo que sobrepasa a la razón (Häberle, 2003).

[1] «We must now return to the core of the first amendment, speech that is explicitly political. I mean by that criticisms of public officials and policies, proposals for the adoption or repeal of legislation or constitutional provisions and speech addressed to the conduct of any governmental unit in the country». 
Lo anterior significa que bajo los presupuestos de un Estado de cultura, el hombre es el principal actor y hacedor de la cultura, que tiene una posibilidad de expansión creativa y con ello también de autorrealización personal (Smend, 1985), un ser intrínsecamente valioso e incompleto que solo encuentra la respuesta plenamente adecuada en el sentir y el querer (Lucas, 2000), un ser altamente autorreflexivo de su realidad que piensa desarrollar su espiritualidad y no conoce más límite cognitivo que su propia imaginación. El arte y, en especial, el derecho a la libertad de creación y expresión artística, como bienes culturales, son para él aspectos trascendentes para su existencia porque contribuye al proceso educacional y formativo de la sociedad $^{[2]}$, al tiempo de fortalecer su identidad cultural individual o colectiva (Häberle, 2004).

\subsection{La expresión artística y el lenguaje satírico}

En el ámbito artístico, las expresiones suelen dirigirse a través del uso de un lenguaje sumamente crítico, provocador, burlesco o irónico, pues el artista es una persona que tiende a ocultar bajo su ingenio la exteriorización refinada de su pensamiento. En Hustler Magazine v. Falwell 485 U.S. 46 (1988), la Corte Suprema de los Estados Unidos reconoció expresamente la existencia de un derecho a la crítica muy aguda cuando estas se realizan a través de parodias y sobre todo contra figuras o medidas públicas: «Dichas críticas, inevitablemente, no siempre serán razonadas ni moderadas; las figuras públicas, así como los funcionarios públicos, siempre estarán sujetos a "ataques vehementes, cáusticos y, a veces, desagradablemente incisivos".

En efecto, el ejercicio del derecho a la libertad de expresión artística se asocia por excelencia -y puede ser mejor entendido- con un lenguaje satírico. Para la Real Academia Española, la sátira puede significar un discurso o dicho agudo, picante, mordaz, dirigido a censurar o ridiculizar. Su labor "radica, pues, en objetar o cuestionar lo que el autor percibe en la sociedad. No se trata de la crítica usual, a través de una columna de opinión, en la que una persona suele argumentar a favor o en contra de una postura determinada. Es, en realidad, crítica a través del arte y la creatividad, por lo que merece una tutela adecuada sobre todo si lo que se propone efectuar es una crítica sobre aspectos políticos, religiosos o sociales» (Zea, Pazo y Zelada, 2015, p.19).

A partir de lo indicado puede identificarse algunos elementos que permiten calificar $\mathrm{y} / \mathrm{o}$ valorar una determinada expresión como satírica. Entre ellos, podría mencionarse: 1) la exageración o deformación de la realidad; 2) la crítica mordaz que es una suerte de control social contra un sujeto $u$ objeto; y, 3) el ánimo de provocar, agitar, ridiculizar, ironizar o burlarse de un ámbito de la realidad. Esto es relevante, por cuanto no cualquier manifestación de arte es per se una sátira, ni tampoco puede ser utilizada para propalar directa o subrepticiamente toda clase de insultos. El insulto no tiene amparo constitucional por este derecho y supone un límite a su ejercicio, pues emplea agravios con la finalidad de denigrar a la persona y al respeto de su dignidad.

Ahora bien, la sátira también puede manifestarse en numerosas expresiones. Una de ellas es la burla. Esta se caracteriza por el empleo de un lenguaje jocoso que permite exponer determinadas críticas, las cuales suelen llevar hasta la ridiculización. La doctrina reconoce que la burla puede configurarse como una sátira disminuida o, según el talante de la misma, como una sátira igualmente mordaz. También, tenemos a la parodia, en donde el parodista crea su obra artística mediante la destrucción de otra, utilizando diversos recursos expresivos (imitación, modificación, etc.). Por ello, sus «contenidos [son] críticos en el sentido destructor del término, [pues] en la parodia la crítica que no sea destructiva no tiene cabida» (Sol, 2005, p. 126). Frente a este tipo de sátira, aparece la caricatura, la cual es otra manifestación de la libertad de expre-

[2] Es menester resaltar que el artículo 14 de la Constitución Política señala que a través de la educación se promueve el conocimiento, el aprendizaje y la práctica de las artes. Asimismo, el artículo 18 indica que la educación universitaria tiene como fines la formación profesional, la difusión cultural, la creación intelectual y artística y la investigación científica y tecnológica. 
sión artística y más evidente en el dibujo, la pintura e, incluso, en la escultura. Se diferencia de la parodia, porque la caricatura alcanza los aspectos externos, aparentes o físicos y la deformación se produce por la exageración hacia la ridiculización; en cambio, la parodia alcanza a la esencia, el espíritu de las cosas, su significado y contenido expresivo (Sol, 2005).

\subsection{El derecho a la irreverencia como conte- nido implícito de la libertad de expresión artística}

Si bien el contenido de un derecho fundamental puede encontrarse en el mismo texto de la disposición normativa, existen algunos casos en los cuales el surgimiento de determinadas circunstancias o valoraciones tienden a reformular o extender sus alcances para garantizar al más alto nivel el disfrute de los bienes humanos. En este supuesto, el contenido normativo del derecho fundamental se configura a partir de un conjunto de variables jurídicas o metajurídicas y no por el mero reconocimiento expreso en algún instrumento jurídico.

Así, como expresa Luis Castillo (2008), el «contenido implícito nuevo de un derecho fundamental es el o los elementos conformantes del contenido que son fruto del redimensionamiento del derecho humano y del bien humano que está detrás de todo derecho humano, que ocurre en un momento determinado por el cambio de las circunstancias o de las valoraciones sociales» (p. 13). En esa misma línea, el Tribunal Constitucional sostuvo en el Expediente $\mathrm{N}^{\circ}$ 0895-2001-AA/TC que «existen determinados contenidos de derechos fundamentales cuya necesidad de tutela se va aceptando como consecuencia del desarrollo normativo, de las valoraciones sociales, de la doctrina y, desde luego, de la propia jurisprudencia constitucional» (fundamento 5).

Definitivamente, no cualquier aparición circunstancial en el plano de los hechos merece un nuevo reconocimiento constitucional y para ello consideramos necesario acudir a las vías normativas previstas en el artículo 3 de la Constitución Política, es decir, evaluar si se trata de un derecho inspirado en la dignidad del ser humano, en los principios de soberanía, el Estado democrático de derecho y en la forma republicana de gobierno.
En tal sentido, de acuerdo con lo desarrollado en el acápite anterior, se ha podido apreciar que el ejercicio de la libertad de expresión a través del arte plantea una concepción singular respecto a la forma cómo el ser humano exterioriza sus ideas y opiniones, las mismas que por la naturaleza propia de la expresión contienen un grado mucho mayor de crítica, a la que denominamos irreverente, precisamente, por el empleo de la sátira como técnica o estilo lingüístico.

La irreverencia nos sugiere la idea de una expresión o conducta expresiva que no se identifica con los cánones convencionales o conservadores, sino más bien, con aquellas concepciones ofensivas, revolucionarias y heterodoxas. La Real Academia Española la define como aquello contrario al respeto debido, lo que permitiría explicar por qué en el mundo artístico muchas veces las creaciones no se condicen con los parámetros socialmente aceptados; por el contrario, se elaboran y difunden objetos que en rigor resultan ser calificados como hirientes, denigrantes o reprochables para un grupo de personas y dentro de un contexto determinado.

Para conocer la importancia que tiene comprender el contenido de este derecho cabe recordar el famoso caso de las "Caricaturas de Mahoma», publicadas por el diario danés Jyllands-Posten en el 2005. Al respecto, Robert Post (2005) describió las serias repercusiones que generaron estos dibujos que mostraban al profeta árabe con símbolos islámicos, con un turbante en forma de bomba y enfrentando a una larga línea de terroristas suicidas, ya que ello trajo una ola de disturbios en todo el mundo y acabó con unas consecuencias sumamente espeluznantes: la muerte de 139 personas, ofrecimientos de pagos para matar a los humoristas, el cierre de los diarios, despidos y encarcelamiento de los editores, etc.

Estos sucesos tuvieron un gran impacto a nivel internacional, pues diversos pensadores y literatos, preocupados por lo ocurrido, se mostraron más cautos al momento de expresar sus opiniones mediante el arte. Inclusive, Mario Vargas Llosa (2006), en un artículo para el diario español El País, reflexionó sobre la probable desaparición del derecho a la irreverencia que garantiza toda libertad de expresión artística: «¿Puede llegar a ocurrir lo mis- 
mo algún día en la Europa de Voltaire, la de las luces, la que instauró como un principio básico de la civilización el derecho de crítica, de irreverencia, no solo ante los gobiernos; también, ante los dioses, la libertad de expresión y la convivencia de diversos credos, costumbres e ideas en una sociedad abierta? Vale la pena preguntárselo porque, a raíz del escándalo de las viñetas blasfemas, una buena parte de la Europa que disfruta de esa cultura de la libertad ha mostrado una prudencia o desgano en la defensa de lo mejor que tiene y que ha legado al mundo, que parecería que el poder de intimidación del extremismo islamista comienza también a tener efectos estupefacientes en el corazón mismo de la cuna de la democracia».

Y si avanzamos unos años más, podríamos evocar la fatídica tragedia ocurrida en París contra el semanario Charlie Hebdo en el año 2015, donde grupos fundamentalistas radicales atacaron el local de la revista, asesinando a sus dibujantes por la publicación de caricaturas satíricas de índole religiosa y dejando heridos a varios periodistas y algunos artistas gráficos.

Todo ello motivó que, por ejemplo, la Asamblea Parlamentaria del Consejo Europeo decidiera reconocer en la Resolución N.$^{\circ} 2031$, del 27 de enero de 2015, que el uso de la sátira irreverente, la información o ideas que ofenden, conmocionan o perturban, así como las críticas a la religión forman parte del ámbito protegido por el derecho a la libertad de expresión contenida en el artículo 10 del Convenio Europeo de Derechos Humanos, en tanto exigencias del pluralismo y la tolerancia propias de una sociedad democrática.

La jurisprudencia tampoco ha sido esquiva a la especial consideración que subyace en el ejercicio de la libertad de expresión artística, aunque no enarbolando un derecho a la irreverencia específicamente. No obstante, creemos que dicha omisión no significa su desconocimiento: antes bien, existen algunos fallos cuyos razonamientos asientan el carácter irreverente que evocan las opiniones 0 críticas vertidas a través del arte. Por ejemplo, en el caso Joseph Burstyn, Inc. v. Wilson 343 U.S. 495 (1952), el Tribunal Supremo de los Estados Unidos evaluó si el contenido de una película era contrario a una ley que censuraba el sacrilegio. El Alto
Tribunal, en sus argumentos, dejó establecido que ninguna religión podría servir de límite a la libertad de expresión, puesto que reconocer la constitucionalidad de dicha norma equivaldría a favorecer a una religión sobre otras, o callar las expresiones de los sentimientos sagrados impopulares por una minoría religiosa. Por tanto, estimó que el Estado no tenía legítimo interés para la protección de puntos de vista desagradables de cualquiera o todas las religiones y que no podía reprimir ataques reales o imaginarios de una doctrina religiosa en particular, ya sea que aparezcan en publicaciones, discursos o imágenes en movimiento (vale decir, en películas). Esta decisión permite advertir que en las prácticas artísticas debe existir un margen alto de tolerancia frente a la blasfemia, que no es otra cosa que una modalidad del derecho a la irreverencia en el ámbito religioso.

También, en el caso Eon v. Francia, el Tribunal Europeo de Derechos Humanos sostuvo que «la sátira es una forma de expresión artística y un comentario social que, por sus características inherentes de exageración y distorsión de la realidad, naturalmente tiene como objetivo provocar y agitar. En consecuencia, cualquier interferencia con el derecho de un artista, o de cualquier otra persona, de usar este medio de expresión debe examinarse con especial cuidado». Este pronunciamiento, evidentemente, es una muestra que el lenguaje satírico desarrolla la naturaleza irreverente de la expresión artística.

En suma, es innegable que todo el contexto antes descrito permite construir dogmática, normativa y jurisprudencialmente un derecho a la irreverencia como contenido implícito de la libertad de expresión artística, el cual no solo radica en la dignidad de la persona, sino que se convierte en una garantía objetiva para fortalecer nuestro sistema democrático y republicano de gobierno que redundará a su vez en una vía de acceso a la cultura y la formación de una opinión pública libre.

\subsection{Titulares del derecho a la libertad de ex- presión artística}

Un aspecto que ha generado cierta discusión es el relativo a la titularidad de esta libertad fundamental. Y es que, por su contenido mismo, la doctrina ha precisado que aquel solo puede ser ejercido 
por los «artistas», es decir, por aquellas personas que estén vinculadas inescindiblemente con el conocimiento artístico, como los profesionales de las escuelas de arte.

Sin embargo, contrario a ello, sostenemos que la libertad de expresión artística puede ser ejercida por cualquier persona, al momento de utilizar su plena creatividad para exteriorizar determinadas ideas u opiniones. Por ejemplo, en Masterpiece Cakeshop, Ltd. Et al., Petitioners v. Colorado Civil Rights Commission, Et Al. 584 U.S. (2018), el juez Thomas de la Corte Suprema de los Estados Unidos arguyó que las tortas de boda, elaboradas por un repostero, representan expresiones artísticas protegidas por la primera enmienda: «Phillips' creation of custom wedding cakes is expressive. The use of his artistic talents to create a well-recognized symbol that celebrates the beginning of a marriage clearly communicates a message [...] By forcing Phillips to create custom wedding cakes for same sex weddings, Colorado's public-accommodations law "alter[s] the expressive content" of his message».

En tal sentido, no puede desconocerse la titularidad del derecho a partir de los gustos o preferencias que tenga una sociedad. Hacerlo, significaría dejar al libre subjetivismo de terceros el reconocimiento de la dignidad humana en la que se funda esta libertad fundamental. Por eso, la preocupación no debe residir en determinar quiénes son artistas, por cuanto esa condición reside el mundo interno de todo ser humano cuando expresa sus pensamientos y tampoco dicha valoración debe limitarse a una concepción de lo comúnmente bello, correcto o moralmente aceptado.

\subsection{La participación de terceros intermediarios}

La exhibición del arte constituye un momento en el que el artista pone en conocimiento del público el fruto de su invención. Dicha acción —en algunos casos- puede ser realizada por el mismo sujeto, así como también con el apoyo de terceros, tal es el caso de un editor de novelas, el vendedor de boletos para una obra de teatro y entre otros. Así, por la participación directa en la difusión de las expresiones, a la persona intermediaria se le extiende la protección y restricciones que corresponden al derecho a la libertad de expresión artística.
Desde luego, no se trata aquí de cualquier tercero, sino de aquellos que contribuyen decisivamente a que la creación artística llegue al público. Como lo ha sostenido el Tribunal Constitucional Federal de Alemania en BVerfGE 30, 173, 54 [Mephisto]: «La Ley Fundamental garantiza plenamente la libertad de ejercer una actividad en el campo artístico. Por ello, en la medida en que se requiera de la actuación de intermediarios (así como de medios publicitarios) para establecer una relación entre el artista y el público, también las personas que ejercen una actividad mediadora de este tipo se encuentran protegidas por la garantía de libertad artística. Como una obra de arte narrativa sin distribución ni publicación no podría ser eficaz en el público, la editorial representa un intermediario indispensable entre los artistas y el público y la precitada garantía se extiende también a sus actividades. Por lo tanto, el solicitante como editor de la novela puede ser afectado en su derecho fundamental de libertad artística».

\subsection{Contenido}

\subsubsection{Derecho a crear arte}

Comprende el ámbito de elaboración de la obra artística, el cual no admite intervención alguna por parte del Estado y de los particulares. Además, se considera una facultad absoluta en la medida que no conoce límites y responde únicamente a los métodos y técnicas que emplea el artista para la difusión de sus ideas u opiniones.

\subsubsection{Derecho a difundir arte}

Se refiere al ámbito de exhibición del arte, esto es, cuando el artista desea compartir con terceros el producto de su invención. Este escenario es más bien relativo, ya que puede hallar límites en el respeto de otros bienes fundamentales, como el derecho al honor, a la imagen, la libertad religiosa, etc.

\section{LÍMITES A LAS EXPRESIONES ARTÍSTICAS EN EL ANÁLISIS DE CASOS EMBLEMÁTICOS}

\subsection{Corte Constitucional de Colombia: Sen- tencia SU 626/15 (1 de octubre de 2015)}

El señor Fernando Beltrán interpuso una acción de tutela contra el Museo Santa Clara y el 
Ministerio de Cultura, considerando que la exposición Mujeres Ocultas, de la artista María Eugenia Trujillo Palacio, había vulnerado su derecho al libre desarrollo de la personalidad y a la libertad de cultos. El actor sostuvo que dicha exposición artística empleó objetos de la religión católica con sugestivas representaciones del cuerpo femenino, como por ejemplo los tabernáculos que custodian las hostias, acompañadas de imágenes con vaginas, las cuales fueron denominadas por la artista como: «la golosa», «la chiquita», «la morena», «la destrozada», «la dulzona», «alguien dentro del pecho erige soledades», etc.

La corte al evaluar el caso emitió una sentencia de unificación de criterios, sosteniendo que el arte, por ser un concepto bastante amplio y complejo que impide delimitar pristinamente su margen de acción y protección, necesita de una serie de parámetros orientadores para la resolución de un conflicto. En tal sentido, puntualizó lo siguiente: 1) la exclusión de una actividad como artística no puede depender únicamente de una decisión mayoritaria o de una defensa minoritaria; 2) la opinión de una comunidad de expertos, el reconocimiento hecho por el autor o por el público, así como la existencia de una tradición que indique que una expresión es considerada artística, constituye un referente imprescindible y, en esa medida, por ejemplo, los conceptos emitidos por los comités curatoriales de los museos deben ser siempre valorados; 3) el legislador, titular de la cláusula general de competencia, tiene una amplia facultad para reconocer las expresiones que constituyen una actividad artística o cultural y, en consecuencia, establecer para ellas un régimen jurídico; 4) la competencia del legislador no es absoluta, pues de ser ello quedaría librada a la discrecionalidad de las mayorías políticas dicho reconocimiento, propiciando por esa vía la exclusión de determinadas actividades de la protección constitucional del arte; y, 5) excluir una expresión de creatividad o ingenio humano como actividad artística - cuando dicha condición se desprende de la aplicación de las reglas anteriores- solo será posible después de ser sometida a un juicio especialmente exigente que logre desvirtuar la presunción de cobertura (fundamento 6.4.2.).

De esta forma, el arte, si bien es otra modalidad más de expresión, debe apreciarse -a su vez - como una verdadera manifestación cultural, cuya relación (arte-cultura) exige al Estado adoptar acciones positivas como: 1) el cumplimiento del deber de enseñar, para garantizar su conocimiento y aprehensión, 2) promover y fomentar su acceso y, 3) crear incentivos a fin de facilitar su libre práctica; así como, acciones negativas consistentes en abstenerse de interferir en la faceta de gestación y difusión artística. Esto último, es justamente aplicable en materia religiosa, en donde las convulsiones sociales exigen del Estado laico el respeto por el principio de neutralidad religiosa y un adecuado balance entre tales acciones, evitando favorecer 0 afectar directamente a una religión o iglesia.

Con toda esta protección reforzada, la corte consideró que si bien en el ejercicio de la libertad de religión se adscribe el deber de abstenerse a ejecutar actos que constituyan un agravio a los símbolos, objetos o sentimientos religiosos, dicha libertad no es ilimitada ni puede avasallar a aquellas otras libertades culturales como la artística.

Por consiguiente, no encontró que la exposición Mujeres Ocultas se halle restringida por las categorías que limitan a la libertad de expresión, es decir, que se trate de una propaganda de guerra, que verse sobre pornografía infantil o posea la intención de exacerbar el odio o la violencia religiosa, puesto que, a pesar de causar molestias para algunos católicos, el mero disgusto social no logra acreditar una infracción a la libertad de religión. Por el contrario, es el artista quien dando vida a su capacidad creativa elaboró y construyó sus propios objetos de arte - sin sustraer o alterar los bienes del culto- para dotarle de un contenido autónomo y transmitir su mensaje crítico al público en un establecimiento, exclusivamente, creado para ese fin.

Además, el acceso a las obras parte de la concurrencia voluntaria de los espectadores, en su deseo por conocer, apreciar o criticar la posición del artista y, en nada interfiere en la decisión de elegir, abandonar, cambiar o rechazar una doctrina de fe. Ello, en efecto, redunda en el hecho de que el Estado no se inmiscuye en la decisión de la persona ni ejecuta políticas para obligar a la ciudadanía a presenciar el arte.

Finalmente, respecto a la prohibición de la exposición artística, la corte realizó el test de pro- 
porcionalidad para determinar si ello afecta o no la libertad de expresión. En consecuencia, concluyó que siendo la restricción a la obra una medida idónea, pues pretende proteger la libertad religiosa de los demandantes, ella no es necesaria si se cuenta con la posibilidad de optar por el libre ingreso a la exposición, antes que preferir el veto absoluto. Incluso, acudiendo a la proporcionalidad en sentido estricto, resaltó que cercenar el deber de promoción de la actividad artística y cultural con la prohibición de las Mujeres Ocultas significaría una afectación especialmente grave que atentaría con el deber neutral que le toca asumir al Estado en el mercado plural de las ideas.

\subsection{Corte Suprema de los Estados Unidos: Hust- ler Magazine v. Falwell, 485 U.S. 46 (1988)}

En la edición de noviembre de 1983 de la revista Hustler Magazine se publicó una parodia del licor Campari, que contenía la imagen de Jerry FaIwell -conocido ministro religioso y comentarista sobre temas políticos y de interés público - bajo el título Jerry Falwell talks about his first time 'Jerry Falwell habla sobre su primera vez'. En ella se retrataba el formato real del anuncio y se confeccionó una supuesta entrevista, en donde él explicaba que su primera vez había sido un encuentro incestuoso con su madre, en una letrina y en estado de ebriedad. Además, dicha caricatura agregó como leyenda en su parte final: «Parodia publicitaria. No debe interpretarse seriamente». Asimismo, el índice de la revista fue incluida en la sección «Ficción; Parodia publicitaria y sobre personalidades».

Frente a estos hechos, el señor Falwell demandó por daños y perjuicios a Hustler Magazine Inc., Larry Flynt y Flynt Distributing Co., Inc., y recibió una fuerte indemnización. Esta decisión fue confirmada por el Tribunal de Apelaciones, por lo que el representante de la industria demandada decidió interponer una acción ante la Corte Suprema dada la presunta violación a la primera y decimocuarta enmienda.

En voto unánime, la Corte recordó en un primer momento la opinión del juez Frankfurter cuando sostuvo en Baumgartner v. United States, 322 U.S. 665, 673-674 (1944) que una de las prerrogativas de los ciudadanos estadounidenses es el dere- cho a criticar a las figuras públicas y a las medidas públicas, la cual, inevitablemente, no siempre serán razonadas ni moderadas, pudiendo, incluso, estar sujetas a ataques vehementes, cáusticos y, a veces, desagradablemente incisivos.

Así, en relación a lo expuesto precedentemente, el juez ponente Rehnquist añadió que, en algunas ocasiones, el arte de los parodistas o caricaturistas no es racional ni imparcial, sino incisivo y arbitrario, pues las tiras cómicas o caricaturas políticas tienden a explotar rasgos físicos o acontecimientos políticos bochornosos, que suelen afectar sentimientos de las personas que le sirven de referencia. Situación que -independientemente de su verdad o falsedad- no las exime del reconocimiento en la primera enmienda, máxime si estas han tenido un papel destacado en el debate público y político de la historia norteamericana.

Con estas afirmaciones, el Supremo Tribunal precisó que para admitir el carácter ultrajante de la caricatura en el ámbito del discurso político y social debe fundamentarse en un estándar objetivo que determine un impacto psicológico adverso en el público y no subjetivo que recaiga en la desaprobación del ofendido.

Asimismo, argumentó que esto no significa que cualquier expresión acerca de una figura pública esté exenta de sanción resarcitoria, sino que debe analizarse si las expresiones falsas son realizadas con «real malicia» o «intención dolosa», esto es, con conocimiento de que la afirmación era falsa o con desconsideración temeraria sobre su veracidad o falsedad. Dicho esto, toda vez que en el caso eso no fue probado, la corte decidió revocar el fallo emitido por el tribunal federal.

\subsection{Tribunal Constitucional Federal de Alemania: BVerfGE 75, 369 (3 de junio de 1987)}

Se había publicado en la revista Konkret varias caricaturas sobre el ministro bávaro Franz Josef Strauß con la apariencia de un cerdo que mantenía relaciones sexuales. En la primera caricatura, se mostraba al cerdo copulando sobre otro vestido de juez; en la segunda, aparecían varios cerdos realizando diversas actividades sexuales, y en la tercera se encontraban más cerdos con indumentaria judicial y practicando las cópulas sexuales. El título del 
primer dibujo decía: «La sátira puede hacer cualquier cosa: ¿Rainer Hachfeld ${ }^{[3]}$ también?»; el segundo título expresaba: «¿Qué dibujo es el correcto, por fin, señor fiscal?»; el tercer dibujo venía precedido de una carta que reclamaba retratar más cerdos porque el ministro iba a tener bastante actividad. Por estos hechos, el caricaturista fue condenado por difamación contra el referido político, imponiéndole una multa por cada uno de los dibujos.

El Alto Tribunal alemán consideró que tales dibujos eran una práctica artística, porque representaban una acción creativa libre e impregnada de impresiones y experiencias exhibidas por el artista, por tanto, el hecho de expresar una opinión controvertida no la descalificaba para buscar tutela constitucional. También, resaltó que el uso de la sátira en el mundo de las caricaturas constituye parte estructural de esta clase de género artístico, basado por antonomasia en las exageraciones, distorsiones y distanciamiento del personaje u objeto original. Por ello, la evaluación judicial para estos casos deberá separar la connotación satírica de la palabra y la imagen con el contenido mismo de la caricatura, es decir, analizar de forma separada si tanto el ropaje satírico como el mensaje del dibujo contienen una expresión que muestre desprecio por la persona caricaturizada. Esto, desde luego, coadyuva a tener en cuenta parámetros de apreciación diferentes y, por lo general, menos estrictos cuando se discute sobre las formas utilizadas o el contenido.

Bajo esas premisas, la Corte manifestó que los tribunales locales habían evaluado adecuadamente el presente caso, estableciendo al derecho al honor como límite a la libertad artística del caricaturista, debido a que, si bien el personaje caricaturizado era un actor político expuesto a la constante crítica, se le había asociado con la forma y naturaleza de un animal manteniendo relaciones sexuales que trastocaron su esfera íntima. Así, dichas conductas retratadas gráficamente, más los actos de bestialidad vinculados con la justicia, habían afectado la dignidad del ministro Strauß como persona. Por consiguiente, concluyó que el artista se había excedido de los límites razonablemente permitidos para la difusión de su caricatura, toda vez que en el núcleo del honor personal protegido por el artículo 1.1 de la Constitución existe siempre una afectación grave al derecho de la personalidad.

Lo relevante en la sentencia reside en diferenciar las formas y el contenido del objeto artístico, con el fin de sustentar una decisión que propenda un equilibrio de los derechos en juego. Aquí, no bastó identificar al personaje político como un cerdo copulador, sino que adicionalmente se transmitió el mensaje que aquel tenía a su «disposición el aparato judicial» (Mendoza, 2007, 246). Son estos presupuestos los que motivaron a poner límites a la libertad artística, frenar su irreverencia y relajar los amplios márgenes de crítica a un personaje público vinculado a la esfera política.

\subsection{Tribunal Europeo de Derechos Huma- nos: Case Karatas v. Turquía (8 de julio de 1999)}

El ciudadano turco Hüseyin Karatas publicó en 1991 una antología de poemas titulados El canto de una rebelión, cuyo contenido azuzaba a los grupos insurreccionales de la región Kurda para sublevarse frente a la autoridad. Fue así que el fiscal de Estambul lo acusó de difundir propaganda contra la unidad indivisible del Estado, solicitando inmediatamente la aplicación de la Ley de Prevención del Terrorismo y la confiscación de las copias de su obra. Finalmente, los órganos jurisdiccionales de Turquía determinaron su culpabilidad, condenándolo a prisión más el pago de una multa.

La Corte de Estrasburgo reconoció que la condena al demandante por la publicación de sus poemas se basó en una prescripción legal de lucha contra el terrorismo, cuya finalidad legítima se enmarcaba en la necesidad de proteger bienes jurídicos relevantes como la seguridad nacional, la integridad territorial y la prevención del desorden y el crimen. Sobre la necesidad de la medida restrictiva, sostuvo que para evaluar el caso en concreto habría que tomar en cuenta en primer lugar que el objeto cuestionado se trataba de un producto artístico (poema), para luego analizar los siguientes elementos: 1) el contenido de las declaracio-

[3] Era el nombre del caricaturista. 
nes impugnadas; 2) el contexto en el que fueron hechas; 3) si la restricción resultaba proporcional a los objetivos legítimos perseguidos; y, 4) si los motivos invocados por las autoridades nacionales para justificarla son pertinentes y suficientes. Estos dos últimos puntos vinculados con el examen de proporcionalidad propiamente dicho.

En atención a ello, señaló que, a través del empleo de técnicas literarias como el patetismo y las metáforas, los poemas hacían un llamado al autosacrificio por la ideología del «Kurdistán» e, incluso, había algunas frases agresivas dirigidas a las autoridades turcas que podían incitar a los lectores al odio, la revuelta y el uso de violencia. Actos que Turquía estaba tratando de evitar por años, debido a la ola de violencia perpetrada por movimientos separatistas en la región sudeste.

Asimismo, la corte consideró relevante el hecho que el contenido de los poemas solo iba destinado a una minoría de lectores, a diferencia de lo que hubiera resultado con el empleo de los medios de comunicación masiva. Por tanto, en virtud a la naturaleza artística de la expresión empleada y el reducido impacto sobre la seguridad nacional, el orden público y la integridad territorial, estimó que lo transmitido guardaba relación en mayor grado con una profunda angustia a la situación política del país, que una llamada a la sublevación; por lo que, aunado a la desproporcionalidad de la condena privativa de libertad frente a los hechos, se declaró la vulneración al derecho a la libertad de expresión.

En esta sentencia, la Corte tuvo que apoyarse de otros criterios - como la técnica de elaboración y la inspiración del artista- para fundamentar su decisión a través de la observancia del test de proporcionalidad. Así, pues, se trata del primer pronunciamiento del Tribunal Europeo que más se acerca a la dimensión objetiva de la libertad de expresión artística, pues parte por entender que el controvertido poemario, siendo una obra de arte, tenía como trasfondo un cariz político que versó sobre un asunto de interés público, lo cual admite una crítica más amplia en relación a los asuntos de gobierno. De esta forma, tanto la creación del arte como el ámbito de su difusión resultan medibles para determinar la razonabilidad y proporcionalidad de la injerencia a la expresión artística, la misma que puede elevar su estándar de protección en función a su contenido (en este caso político).

\section{CENSURA Y ¿RECTIFICACIÓN? DE LAS EX- PRESIONES ARTÍSTICAS}

El ejercicio del derecho a la libertad de expresión (artística) no está sujeto a censura, sino únicamente a la imposición de responsabilidades ulteriores. Ello en la medida que dicha restricción esté prevista por ley, se sustente en una finalidad legítima y sea necesaria para una sociedad democrática.

Por eso, en un Estado constitucional de cultura no cabe admitir la represión de las manifestaciones de arte atendiendo exclusivamente al contenido que encierran sus ideas o la poca esteticidad de su elaboración. Debe garantizarse su máxima difusión, en la medida que fortalece la identidad de las personas, contribuye a un desarrollo educativo más humano y crítico, y robustece los cimientos de nuestro sistema democrático.

De esta manera, si bien el artículo 13.4 de la Convención Americana de Derechos Humanos prevé que los espectáculos públicos pueden ser sometidos a censura previa con el objeto de proteger la moral de la infancia y la adolescencia, esto no puede ser analizado desde una perspectiva literal, pues tales espectáculos perfectamente pueden ostentar carácter artístico y, por ende, ser pasible de una tutela especial que garantice el acceso a la cultura de las personas.

Por ejemplo, en la sentencia T-104/96, del 8 de marzo de 1996, la Corte Constitucional de Colombia impidió la censura de una exposición pictórica de cuadros eróticos (en la sala de una institución pública) que eran presenciados por niños y adultos. Sustentando su decisión en el deber que existe en promover un desarrollo integral a los menores, ordenó que el Estado, en colaboración con los padres de familia, fomenten una adecuada educación sexual, de manera que sean capaces de reaccionar en base a lo que van construyendo como moral y estéticamente aceptable (apartado 4).

Lo anterior, sin embargo, no predica el amparo absoluto de esta libertad fundamental, solo reconoce la singular dimensión que ocupa la libertad de expresión en el ámbito artístico. $Y$ es que cuando tales expresiones son emitidas de forma indebida no deben ser toleradas por el Estado ni 
la sociedad. Así, las personas podrán interponer las acciones civiles o penales que el ordenamiento jurídico les reconozca e, incluso, solicitar su rectificación en forma gratuita, inmediata y proporcional.

La rectificación es un derecho fundamental consagrado en el artículo 2.7 de la Constitución Política que procede cuando se difunde información inexacta o se emitan expresiones que agravien el honor de las personas. Empero, cuando tales afrentas se realizan mediante imágenes estáticas o en movimiento surgen dudas respecto a la posibilidad de que estas puedan rectificarse, ya que no se trata de opiniones escritas o verbales que puedan ser fácilmente corregidas. Es decir, si se determina que una parodia o imitación artística vulnera el derecho al honor y a la imagen de una persona ¿habría la necesidad de efectuar otra caracterización que no distorsione ni exagere los rasgos del sujeto?, con lo cual ¿no significaría ir en contra de la esencia de este tipo de arte?

Nuevamente, la Corporación colombiana ha tenido la ocasión de examinar un caso similar en la sentencia T-787/04, del 18 de agosto de 2004, en donde la profesora Rosa Peña Carabalí había solicitado que el artista Caleb Avendaño Mosquera rectifique la información divulgada en su caricatura La Flor del Trabajo (propalada en diferentes ambientes públicos y medios de comunicación), por afectar sus derechos a la intimidad, al buen nombre y a la honra. Al respecto, la Corte amparó la acción de tutela sosteniendo que «las personas a quienes se les ha vulnerado sus derechos a la intimidad, al buen nombre y a la honra, tienen derecho a la rectificación del infractor en condiciones de equidad, lo cual exige la satisfacción de por lo menos dos condiciones esenciales, en primer lugar, que la aclaración tenga un "despliego informativo equivalente" a aquel que produjo la infracción; y, además, debe existir la aceptación o reconocimiento de la infracción cometida» (fundamento 33). Finalmente, dispuso que el mencionado dibujante proceda con dicha rectificación en medios escritos y radiales a través de un texto expresamente redactado por el Tribunal, en el que se indica que las caricaturas eran contrarias a la realidad.

En suma, queda claro que el derecho a la rectificación no solo puede invocarse respecto de expresiones escritas o verbales, sino también cuando estas se difundan a través de cualquier figura artística capaz de transmitir información o ideas que lesionen los derechos fundamentales de las personas.

\section{CONCLUSIÓN}

La libertad de expresión artística es un derecho fundamental que no goza de un mínimo desarrollo dogmático o jurisprudencial en nuestro ordenamiento nacional e interamericano, a diferencia de lo que sucede en otras latitudes geográficas o el sistema europeo de protección de derechos humanos. En ese sentido, a través de este trabajo se ha expuesto la necesidad de entender que su ejercicio goza de una singular particularidad en la medida que se inserta en la dimensión cultural del Estado constitucional, el cual concibe a la persona como un ser culto, reflexivo y altamente crítico por el influjo de las artes.

Así, las ideas u opiniones satíricas que se emiten mediante las formas artísticas permiten apreciar que esta libertad comunicativa comprende a su vez el reconocimiento de un derecho a la irreverencia como contenido implícito, lo que permite garantizar que las fotografías, películas, caricaturas y por qué no los memes y otras expresiones apoyadas con la tecnología, se caracterizan precisamente por sus críticas vehementes, desagradables y contrarias a lo moral, social y políticamente correcto.

\section{REFERENCIAS BIBLIOGRÁFICAS}

\section{Libros, revistas y periódicos}

Bork, R. (1971). Neutral Principles and Some First Amendment Problems. Indiana Law Journal, vol. $47, \mathrm{~N}^{\circ} 1$, p. 29.

Castillo, L. (2008). Justificación y significación de los derechos constitucionales implícitos. Pirhua. Lima: Universidad de Piura.

Cordero, A. (1999). La desinteresada imaginación artística. Revista de Filosofía de la Universidad de Costa Rica, vol. 37. Costa Rica, p. 91.

Faúndez, H. (2004). Los límites de la libertad de expresión. México: Universidad Nacional Autónoma de México. 
Häberle, P. (2000). Teoría de la Constitución como ciencia de la cultura. Madrid: Tecnos, p. 28.

Häberle, P. (2003). El Estado Constitucional. Lima: Fondo Editorial PUCP y Universidad Nacional Autónoma de México, p. 117.

Häberle, P. (2004). Nueve ensayos constitucionales y una lección jubilar. Lima: Palestra Editores, p. 204.

Lucas, P. (2000). Teoría general de las relaciones constitucionales. Madrid: Dykinson, p. 56.

Martínez, R. (2014). Arte, derecho y derecho al arte. Revista Derecho del Estado. Nueva Serie, N. ${ }^{\circ}$ 32. Bogotá: Universidad Externado de Colombia, p. 42.

Meiklejohn, A. (1961). The First Amendment Is an Absolute. En: Supreme Court Review, N. ${ }^{\circ} 245$, p. 3.

Mendoza, M. (2007). Conflictos entre derechos fundamentales. Expresión, información y honor. Lima: Palestra Editores.

Pau, Antonio y J. María Roca (2009). Arte y Poder. En: Estado y cultura. Madrid: Fundación Coloquio Jurídico Europeo.

Post, R. (2005). Religión y Libertad de Expresión: retratos de Mahoma. Revista Argentina de Teoría Jurídica, vol. 6, único número. Buenos Aires, pp. 24-25. Recuperado de: http://revistajuridica.utdt.edu/ojs/index.php/ratj/article/ view/244/202

Rubio, M. (2009). El Sistema Jurídico. Introducción

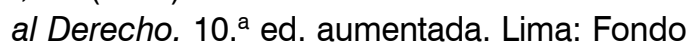
Editorial PUCP, p. 79.

Smend, R. (1985). Constitución y Derecho Constitucional. Madrid: Centro de Estudios Constitucionales, p. 56.

Sol, M. (2005). El régimen jurídico de la parodia. Madrid: Marcial Pons, pp. 198-200.
Vargas, M. (12 de febrero de 2006). El derecho a la irreverencia. El País. Recuperado de: https://elpais.com/diario/2006/02/12/opinion/1139698806_850215.html

Zea, E.; Pazo, O. y Zelada, K. (2015). Sátira religiosa y libertad de expresión. Pautas para el análisis de un conflicto recurrente en las sociedades modernas. En: Serie Libertades Comunicativas, año 2, núm. 2. Lima: Instituto de Derechos Humanos y Desarrollo USMP.

\section{Sentencias y resoluciones}

Asamblea Parlamentaria del Consejo de Europa. (2015). Resolución N. ${ }^{\circ}$ 2031: Ataques terroristas en París: juntos para una respuesta democrática. Recuperado de: http://www.assembly.coe.int/nw/xml/XRef/Xref-XML2HTMLen .asp?fileid $=21444 \&$ lang $=$ en

Corte Constitucional de Colombia. Sentencia SU $626 / 15$.

Corte Constitucional de Colombia. Sentencia T-787/04.

Corte Constitucional de Colombia. Sentencia T-104/96.

Corte Suprema de los Estados Unidos. Case Hustler Magazine v. Falwell, 485 U.S. 46 (1988).

Corte Suprema de los Estados Unidos. Case Joseph Burstyn, Inc. v. Wilson 343 U.S. 495 (1952).

Tribunal Constitucional Alemán. BVerfGE 30, 173, 54 [Mephisto].

Tribunal Europeo De Derechos Humanos. Case Eon v. Francia.

Tribunal Europeo De Derechos Humanos. Case Vereinigung Bildener Künstler v. Austria.

Tribunal Constitucional. Expediente 0895-2001AA/TC. 